Neurosurg Focus 26 (5):E17, 2009

\title{
The evolution of cerebral revascularization surgery
}

\author{
Melanie G. Hayden, M.D., M.A.S., Marco Lee, M.D., Ph.D., F.R.C.S., \\ Raphael GuZman, M.D., and Gary K. STeinberg, M.D., Ph.D. \\ Department of Neurosurgery, Stanford University Medical Center, Stanford, California
}

\begin{abstract}
Among the relatively few surgeons to be awarded the Nobel Prize was Alexis Carrel, a French surgeon and pioneer in revascularization surgery at the turn of the 20th century. The authors trace the humble beginnings of cerebral revascularization surgery through to the major developments that helped shape the modern practice of cerebral bypass surgery. They discuss the cornerstone studies in the development of this technique, including the Extracranial/ Intracranial Bypass Study initiated in 1977. Recent innovations, including modern techniques to monitor cerebral blood flow, microanastomosis techniques, and ongoing trials that play an important role in the evolution of this field are also evaluated. (DOI: 10.3171/2009.3.FOCUS0931)
\end{abstract}

KEY WORDS $\quad$ cerebral revascularization $\quad$ extracranial-intracranial bypass
superficial temporal artery-middle cerebral artery bypass $\bullet$
history of neurosurgery $\quad \bullet \quad$ Carotid Occlusion Surgery Study $\quad \bullet \quad$ carotid artery occlusion

$\mathrm{T}$ HE story of how cerebral revascularization surgery came into common practice, fell from favor, and reemerged as an effective treatment for specific diseases has developed over the last century and a half. Here we explore the exciting history, current applications, and future developments of cerebral revascularization surgery, with a specific focus on STA-MCA bypass. Through this comprehensive review of the literature, we describe the most prominent trends of the last 50 years, incorporating recent insight and innovation.

It is a sobering thought that just over 50 years ago, most strokes were thought to be due to vasospasm, and it was Fisher ${ }^{19}$ who widely promoted the concept that stroke was associated with CA disease. Even now, symptomatic CA occlusion carries an overall risk of subsequent stroke of $2-5 \%$ per year. ${ }^{25,27,37}$

The development of microneurosurgical techniques facilitated the refinement of cerebral revascularization. While EC-IC bypass can be applied with excellent technical results in terms of graft patency (> 95\%), review

Abbreviations used in this paper: $\mathrm{CA}=$ carotid artery; $\mathrm{CBF}=$ cerebral blood flow; COSS = Carotid Occlusion Surgery Study; EC-IC $=$ extracranial-intracranial; ELANA $=$ Excimer Laser Assisted Nonocclusive Anastomosis; ICA = internal carotid artery; JAM = Japan Adult Moyamoya; JET = Japanese Extracranial-Intracranial Bypass Trial; MCA = middle cerebral artery; OEF = oxygen extraction fraction; RECON = Randomized Evaluation of Carotid Occlusion and Neurocognition; STA = superficial temporal artery. of the Extracranial/Intracranial Bypass Study Group of 1985 illustrated the importance of defining which disease processes and hemodynamic states are the most amenable to the procedure. ${ }^{1}$ With limited medical treatments, surgical intervention may be of great benefit to the properly identified patient population.

\section{History}

\section{The Development of Cerebral Microvascular Anastomoses}

The first vascular anastomosis was detailed by Eck in 1877 with his operation on dogs to create a side-to-side anastomosis of the hepatic vein to the inferior caval vein (later known as the Eck fistula). Of the 8 dogs undergoing this procedure, 7 died in 1 week and 1 lived briefly before running away. ${ }^{10}$ French physician Alexis Carrel published an account in 1902 of the first arterial end-to-end anastomosis utilizing fine suture material and triangulation. ${ }^{12}$ For this work and his pioneering the field of vascular surgery and organ transplantation, he was awarded the Nobel Prize for Physiology and Medicine in 1912.

German and Taffel ${ }^{24}$ began to experiment with cerebral revascularization in 1939 with the transposition of a vascular muscle flap onto the cortex in dogs and primates, the first documented encephalomyosynangiosis. Kredel $^{40}$ attempted this in humans in 1942 but later abandoned the procedure due to a high incidence of postoperative seizures. Soon after, in 1949 Beck and colleagues ${ }^{9}$ 
described their revascularization technique of a carotidjugular fistula.

The development of vascular bypass techniques and surgical magnification progressed on separate paths until the 1960s, when the merging of these 2 innovations led to the rapid growth of cerebral microvascular surgery. In 1876, Saemisch introduced the first binocular magnifying device to surgery. ${ }^{28}$ In 1912 surgical microscopes and teleloupes began to be used for experiments. ${ }^{52}$ Despite the prior development of microsurgical techniques and equipment in other surgical subspecialties (for example, otology and ophthalmology), neurosurgeons did not embrace the movement until much later. In 1957, Theodore Kurze $^{42}$ of the University of Southern California was the first to use an operating microscope for neurosurgery. ${ }^{41}$ Following the suggestion of Julius Jacobson (a general vascular surgeon) to use an operating microscope, in 1962 Jacobson with Donaghy reported the first human microsurgical procedure in neurosurgery: an MCA endarterectomy. ${ }^{30,31,42}$ While the first attempt had failed, in the end 2 of the 9 original MCA embolectomies or endarterectomies remained patent. ${ }^{20}$

The convergence of microneurosurgical techniques and more refined understanding of the pathophysiology of cerebral ischemic disease set the stage for the EC-IC bypass. Fisher ${ }^{21}$ had quite astutely stated in 1951, "it is even conceivable that some day vascular surgery will find a way to bypass the occluded portion of the artery." In 1961, Pool and Potts ${ }^{54}$ first attempted cerebral revascularization with a synthetic graft by using a plastic tube to create a STA to anterior cerebral artery shunt. Arteriography performed $<2$ weeks after the operation showed a clotted tube. However, the patient apparently recovered well and was able to return to full-time work. ${ }^{55}$ In 1963 , Woringer and $\mathrm{Kunlin}^{75}$ performed the first EC-IC bypass of the common CA-intracranial ICA using a saphenous vein graft. While overall the patient did not survive, the graft was patent on autopsy.

\section{The Refinement of the EC-IC Bypass}

The actions of the aforementioned pioneers, combined with timely advances in angiography, bipolar, and surgical microscopes, brought cerebral revascularization into the modern era. At this point, Yaşargil, a Turkish native, brought microsurgical techniques into the neurosurgical spotlight. Yaşargil trained in Switzerland under Krayenbühl, and together they published a book in $1965 .{ }^{39}$ That same year, Yaşargil moved to Vermont to join the Donaghy's laboratory. Donaghy had worked closely with Littman to develop microsurgical instruments and needles, eventually founding the Journal of Microsurgery. It was in Donaghy's laboratory in 1961 that Jacobson and Suarez ${ }^{31}$ had previously described the technique of vascular anastomosis using the operating microscope. By the time Yaşargil arrived in Vermont, Donaghy's laboratory was already achieving a $66 \%$ patency rate in experimental microvascular anastomotic techniques. ${ }^{74}$

With perseverance, Yaşargil managed to significantly improve on the original techniques of Suarez and Jacobson. ${ }^{64,74} \mathrm{He}$ incorporated the bipolar technology of Malis to carefully dissect the fragile blood vessels of the brain. While at the University of Vermont, Yaşargil performed the first EC-IC bypass from the STA to a branch of the MCA in a dog. ${ }^{20}$ In 1967, once while in Zürich and then again in Vermont, Yaşargil performed the first EC-IC bypasses in a patient with the purpose of bypassing an occluded ICA. ${ }^{20,77}$ In all, Yaşargil would advance cerebrovascular neurosurgery through significant contributions to the development of the counterbalanced "floating" microscope, novel microsurgical instruments, and aneurysm clips and appliers. ${ }^{70}$

Yaşargil performed the first STA-MCA bypass for moyamoya disease in 1972. The patient was a 4-year-old boy with right hemiplegia and anarthria. He received an end-to-end STA to left insular MCA anastomosis. Two years later, angiography showed improved vascularization and the child's symptoms had improved. ${ }^{38}$ Karasawa and colleagues ${ }^{34}$ achieved good clinical results repeating this procedure in 23 patients with moyamoya syndrome.

Alternatives to the STA-MCA bypass were quick to be developed, and many played a pivotal role in pioneering various intracranial bypass techniques. ${ }^{63}$ Lougheed performed the first EC-IC bypass using a saphenous vein graft in 1971, and Ausman ${ }^{6}$ used a radial artery graft in $1978 .^{68}$ In the 1970s Sundt and colleagues ${ }^{68}$ and others ${ }^{6}$ introduced posterior circulation revascularization. This was used to treat occlusive disease, vertebrobasilar insufficiency, and unclippable aneurysms. ${ }^{13,45}$ This prolific period in the history of cerebral revascularization was accompanied by a determination to increase patient safety during the procedure with improvements in anesthesia, intraoperative monitoring, the use of barbiturates, and hypothermia.

\section{Testing Cerebral Revascularization: The EC/IC Bypass Study Group}

As microneurosurgery progressed, indications for revascularization broadened to include multi infarct dementia, acute stroke, MCA stenosis or dissection, and ischemic retinopathy. To formalize the indications and outcomes of EC-IC bypass, the International Cooperative Study of Extracranial/Intracranial Arterial Anastomosis (EC/IC bypass study) was conducted from 1977 to $1985 .{ }^{2}$ This was an international, multicenter, prospective, randomized study that was to test the concept of STA-MCA bypass surgery as a stroke prevention treatment. Specifically, the study evaluated the value of EC-IC bypass as a means to decrease the subsequent stroke rate for the treatment of "symptomatic atherosclerotic lesions of the internal and/or middle cerebral arteries."

Eligible patients needed to have either stenosis/occlusion of the MCA trunk or ICA above C-2, or a recent (within 3 months) transient ischemic attack or stroke within the MCA/ICA distribution. A total of 1377 patients met these criteria and were randomized to receive either medical treatment (aspirin and hypertension control) or medical treatment in addition to STA-MCA bypass. The surgeries were carried out by cerebrovascular experts, with $>96 \%$ of the bypass grafts patent on follow-up. ${ }^{2}$ The patients had very close follow-up and thorough examinations. 
By the study's close in 1985, the average follow-up was 55.8 months with a minimum of 33 months. While 118 patients were eventually excluded who had initially been randomized, no patient participating in the study was lost to follow-up. The patients with strokes prior to randomization were included in an intent-to-treat analysis. ${ }^{1,2}$

Ultimately, the data of the study suggested EC-IC anastomosis was not better at preventing stroke in patients with atherosclerotic arterial disease of the CA and MCA compared with best medical therapy. ${ }^{2}$ In fact, timing and incidence of both nonfatal and fatal stroke increased in patients receiving both surgery and medical therapy. ${ }^{1}$ Secondary survival analyses were equally discouraging. The study identified 2 important subgroups that appeared to do particularly poorly: patients with severe MCA stenosis and those with persistence of ischemic symptoms in known ICA occlusion. ${ }^{1}$

\section{Reaction to the EC/IC Bypass Study Group}

Following the publication of the EC/IC Bypass Study group's conclusion in 1985, the number of EC-IC cases performed fell precipitously. In North America, insurance companies began to deny coverage for the procedure, and the use of STA-MCA bypass for symptomatic CA or MCA occlusion was nearly abandoned. A similar pattern of decline also occurred in Europe and Asia. It appeared the technical progress could not be supported by the surgical outcomes. ${ }^{8}$ A decade later it was reported that for $42 \%$ of patients undergoing EC-IC bypass, their particular surgeon had performed no bypass procedure during that year. ${ }^{3}$ A rapid decline in residents training in microsurgery followed. As surgeons performed fewer cases overall, mortality rates increased from $2.8 \%$ (19921996) to $5.7 \%$ (1997-2001). ${ }^{3}$

The initial main criticisms of the trial included the presence of bias, lack of generalizability, and the inability to section out particular groups with hemodynamic compromise who could potentially benefit from surgical revascularization. Critics focused on observational, allocation, and "randomization-to-treatment" bias., ${ }^{4,7}$ In 1987, 3 committee reports on the EC/IC Bypass Study appeared in the New England Journal of Medicine, concluding perhaps that the EC/IC Bypass Study population may not have been representative for the population at risk. ${ }^{66}$

Subgroups consequently identified to potentially benefit from surgical revascularization are those in whom hemodynamic factors play a primary role in the precipitation of stroke. Recent technological advances, not available at the time of the EC/IC Bypass Study, have since made it possible to better identify these potential patients. ${ }^{16,36,51,67}$ One such parameter, the OEF as determined by PET identifies patients with hemodynamic susceptibility, who may then benefit from a bypass procedure. . $^{1,25,37,76}$

\section{Present Practices}

Currently, EC-IC bypass is either performed for $\mathrm{CBF}$ augmentation or replacement. Examples of the former would be symptomatic patients with CA occlusion and documented hemodynamic compromise or moy- amoya disease. Bypass surgery for CBF replacement is most frequently performed in complex aneurysm surgery, such as when an aneurysm is trapped, or in skull base tumor surgery associated with vessel sacrifice or injury. $5,7,23,34,35,43,46,47,51,72$ Multiple mechanisms of creating artificial $\mathrm{CBF}$ conduits are available in addition to the already discussed pedicled arterial graft of the STA-MCA anastomosis. An STA-MCA bypass has a patency rate of $>95 \% .{ }^{55,59}$ Other common cerebral revascularization techniques include interposition vein grafts, such as the greater saphenous vein, free arterial grafts including the radial artery, and artificial grafts such as polytetrafluoroethylene tubes. ${ }^{45,69}$

The saphenous vein bypass graft has been used for giant intracranial aneurysms, skull based tumors requiring ICA sacrifice or involving the ICA, VA, or CA occlusive disease..$^{15,22,49,61,62,65}$ Internal CA bypasses include cervical-supraclinoid ICA, petrous-supraclinoid ICA, and cervical-petrous ICA. ${ }^{44}$ The radial artery bypass graft has been shown to have long-term patency when used for treatment of giant aneurysms of the cavernous supraclinoid ICA. ${ }^{29,60}$

Intracranial-intracranial bypasses are occasionally necessary. A short interposition graft such as the patient's own saphenous vein is used. Donor vessels in IC-IC bypasses tend to be from the ICA, $\mathrm{M}_{1}$ or $\mathrm{A}_{1}$ vessels, and the recipients as varied as EC-IC procedures, including the ICA, $\mathrm{M}_{1-3}, \mathrm{~A}_{1-2}, \mathrm{P}_{1-2}$, basilar artery, and superior cerebellar artery.

Important developments in monitoring intraoperative flow have also been made. The use of micro-Doppler, transit time flowmetry, such as the Charbel microflow probes (Transonic), and surgical microscope-based indocyanine green video angiography have all had a positive impact on cerebral revascularization surgery by confirming graft patency and flow.

\section{Measuring Cerebral Hemodynamic Insufficiency: the Oxygen Extraction Fraction}

One of the major criticisms of the EC/IC bypass trial was the assertion that patients with verifiable cerebral hemodynamic insufficiency from carotid occlusion would potentially benefit from revascularization. Only recently have modern technological advancements allowed us to define this subgroup with hemodynamic failure. ${ }^{25}$ The OEF, as measured using PET, helps to determine the hemodynamic susceptibility. It has been shown that patients with increased OEF (Stage II hemodynamic failure) are at increased risk for stroke development. ${ }^{18,25,37,76}$ The OEF can be returned to normal in patients with $\mathrm{CA}$ occlusion who are undergoing EC-IC bypass.

In addition to $\mathrm{OEF}$, other methods exist to assess cerebral hemodynamics and, therefore, define appropriate surgical candidates. These techniques include Xe-CT, SPECT, CT and MR angiography, perfusion CT and MR imaging studies, and digital subtraction angiography. Focus has also shifted to defining the cerebrovascular reserve by a physiological challenge, such as the use of intravenous acetazolamide. Near-infrared spectroscopy has been used to confirm the increase in cerebral blood oxygenation following EC-IC bypass procedure. ${ }^{50}$ Vali- 
TABLE 1: Important past studies on revascularization surgery*

\begin{tabular}{|c|c|c|c|}
\hline Authors \& Year & Study & Hypothesis & Outcome \\
\hline $\begin{array}{l}\text { Anonymous, } \\
1985\end{array}$ & EC/IC Bypass Study & $\begin{array}{l}\text { EC-IC bypass decreases } \\
\text { strokes \& improves } \\
\text { outcomes }\end{array}$ & $\begin{array}{l}\text { op \& medical management fared worse than } \\
\text { medical management alone; nonfatal \& fatal } \\
\text { stroke occurred more frequently \& earlier in } \\
\text { patients undergoing ops; } 30 \text {-day op mortality }\end{array}$ \\
\hline $\begin{array}{l}\text { Grubb et al., } \\
1998\end{array}$ & $\begin{array}{l}\text { Saint Louis Carotid Occlusion } \\
\text { Study }\end{array}$ & $\begin{array}{l}\text { OEF relates to stroke } \\
\text { incidence }\end{array}$ & $\begin{array}{l}\text { ipsilat stroke rate at } 2 \text { yrs in patients } w / \text { normal } \\
\text { OEF is } 5.3 \% \text { compared w/ } 26.5 \% \text { for patients } w / \\
\text { increased OEF }(p=0.004)\end{array}$ \\
\hline $\begin{array}{l}\text { Derdeyn et al., } \\
2002\end{array}$ & $\begin{array}{l}\text { Cost-Effectiveness Analysis of } \\
\text { Therapy for Symptomatic } \\
\text { Carotid Occlusion }\end{array}$ & $\begin{array}{l}\text { PET screening before } \\
\text { selective EC-IC vs } \\
\text { medical treatment }\end{array}$ & $\begin{array}{l}\text { PET screening of the cohort followed by EC-IC } \\
\text { bypass yielded } 23.2 \text { additional QALYs at } \\
\$ 20,000 \text { per QALY compared w/ medical } \\
\text { treatment alone }\end{array}$ \\
\hline \multirow[t]{2}{*}{$\begin{array}{l}\text { JET Study } \\
\text { Group, } 2006\end{array}$} & JET-1 & $\begin{array}{l}\text { Stage II hemodynamic } \\
\text { compromise improves } \\
\text { w/ op bypass }\end{array}$ & $\begin{array}{l}\text { EC-IC bypass surgery reduces the incidence of } \\
\text { major stroke or death in the } 2 \text {-yr period after } \\
\text { op }\end{array}$ \\
\hline & JET-1 subanalysis & $\begin{array}{l}\text { EC-IC bypass changes } \\
\text { brain volume \& } \\
\text { hemodynamics }\end{array}$ & $\begin{array}{l}\text { op increased the affected/unaffected \% regional } \\
\text { CBF ratio }(p<0.03)\end{array}$ \\
\hline
\end{tabular}

* QALY = quality-adjusted life year.

dated outcomes metrics evaluate functional neurological status and neurocognitive status. ${ }^{73}$

\section{Saint Louis Carotid Occlusion Study}

The St. Louis Carotid Occlusion Study, ${ }^{25}$ a prospective cohort analysis, evaluated the prognostic abilities of hemodynamic factors (as determined by $\mathrm{OEF}$ ) for patients with CA occlusion. Factors other than OEF that could have contributed to stroke, including smoking, hypertension, and hypercholesterolemia were controlled. It was found that asymptomatic patients, similar to their symptomatic colleagues in baseline risk factors, had a lower frequency of hemodynamic abnormalities, as determined by significantly elevated OEF. ${ }^{19}$ In comparison with symptomatic patients, the never-symptomatic patients were found to have a lower incidence of elevated OEF, which also correlated to a lower incidence of stroke. ${ }^{56,71}$

Already, PET scans have become commonplace for preprocedure determination of hemodynamic insufficiency. Various smaller studies stratifying patients depending on PET OEF ratios have begun to find improvements in clinical outcome following bypass surgery. For example, a recent study found symptomatic patients with increased OEF indicative of hemodynamic cerebral ischemia had improvements in cognition following bypass (Table 1$).{ }^{58}$

\section{Recent, Ongoing, and Future Studies}

\section{The JET-1 Study}

Like the Carotid Occlusion Surgery Study, the JET is a multicenter, randomized, prospective study of patients with hemodynamic brain ischemia due to cerebral artery occlusive disease. ${ }^{32}$ The JET focuses on patients with
Stage II compromise (misery perfusion), as measured by PET OEF, looking to elucidate the idea of collateral circulation and cerebrovascular reserve. ${ }^{73}$ The study looked at outcomes of $\mathrm{CBF}$ and the progression of neurophysiological function. The analysis revealed a significantly lower incidence of stroke recurrence for patients with Stage II ischemia undergoing bypass surgery than those treated with strict medical therapy. ${ }^{32,53}$

\section{The COSS}

With the role of OEF (as defined by PET) in hemodynamic insufficiency and stroke better defined, the next question is how surgical intervention can change this outcome. The $\operatorname{COSS}^{26}$ is a randomized, controlled study looking at the ability of combined STA-MCA bypass and medical therapy to reduce subsequent ipsilateral ischemic stroke. To participate in the study, patients must have atherosclerotic ICA occlusion with resulting hemispheric symptoms and ipsilateral increased OEF as measured by PET. Examples of excluded patients were those with other causes of cerebral ischemia (for example, moyamoya, vasculitis, and cardiac insufficiency), with anticoagulant medical treatment or planned cerebrovascular surgery. The patients must have a PET OEF that corresponded to their symptoms and imaging. Specifically, the ipsilateral/ contralateral OEF ratio in the MCA territory must be $>$ 1.130. The COSS trial is currently expected to run until 2013.

\section{The RECON Trial}

The RECON trial ${ }^{14}$ is an ancillary study to COSS aimed at assessing the relationship between cerebral hemodynamics and cognitive function in patients undergoing treatment for unilateral $\mathrm{CA}$ occlusion with $\mathrm{EC} / \mathrm{IC}$ 


\section{Evolution of cerebral revascularization surgery}

TABLE 2: Current studies on revascularization surgery

\begin{tabular}{|c|c|c|}
\hline Authors \& Year & $\begin{array}{l}\text { Study } \\
\text { Title }\end{array}$ & Hypothesis \\
\hline Grubb et al., 2003 & coss & $\begin{array}{l}\text { STA-MCA bypass \& medical therapy decreases incidence of subsequent ipsilat ischemic } \\
\text { stroke }\end{array}$ \\
\hline Chmayssani et al., 2007 & RECON & bypass surgery improves cerebral hemodynamics \& cognitive function \\
\hline Miyamoto, 2004 & JAM & $\begin{array}{l}\text { op revascularization is effective for patients } \mathrm{w} / \text { moyamoya presenting } \mathrm{w} / \text { intracranial } \\
\text { bleeding }\end{array}$ \\
\hline JET Study Group, 2002 & JET-2 & stroke recurrence rate for patients w/ Stage I ischemia is decreased after bypass surgery \\
\hline
\end{tabular}

bypass in the COSS trial. Cognitive impairment in association with chronic cerebral hemodynamic insufficiency has often been overlooked. This study will help elucidate whether EC-IC bypass can improve cognitive function or prevent against further cognitive decline.

\section{The JET-2 Study}

The JET-2 study examines the stroke recurrence rate on medical treatment for patients with Stage I ischemia, as determined by cerebrovascular reserve capacity and rest $\mathrm{CBF}$ value. This is determined via paired blood flow studies after a cerebral vasodilatory stimulus. The aim is to be able to determine which patients with Stage I ischemia would have fewer strokes after bypass surgery. ${ }^{73} \mathrm{Ad}-$ ditional follow-up studies to the JET study includes the evaluation of JET-1 subgroups. ${ }^{33}$

\section{The JAM Trial}

The JAM trial is a multicenter randomized trial looking at the efficacy of bypass revascularization for patients with moyamoya disease who present with intracranial bleeding. The aim of the trial is to determine if EC-IC bypass in combination with conservative management can improve prognosis (Table 2). ${ }^{48}$

\section{Novel Bypass Techniques}

The ELANA technique allows for anastomosis of vessels without prior occlusion of the recipient vessel. This is a particularly attractive technique for $\mathrm{CBF}$ augmentation as it avoids the temporary cessation of CBF in a situation in which there is already a vulnerable blood supply. Essentially, the donor vessel is sutured to the recipient vessel together with a platinum ring. An arteriotomy is then performed using an excimer laser and the resultant flap is removed by a suction device. ${ }^{57}$ The current disadvantages of this technique include the relatively high cost, longer procedure time, and the inability of this technique to work on vessel sizes $<2.6 \mathrm{~mm}$.

A recently developed sutureless ELANA technique has the potential to be easier, with shorter procedure times and equivalent patency rates. A recently published laboratory evaluation in rabbits, comparing the ELANA and sutureless ELANA technique, showed that the sutureless ELANA bypass was faster (20 vs 90 minutes), rarely required occlusion (97\%), and had an $89 \%$ patency rate. ${ }^{11}$ These methods can be used for EC-IC and IC-IC bypass.

There is no doubt that revascularization surgery re- mains an important technique in neurosurgery when $\mathrm{CBF}$ augmentation or replacement is required. Just as novel suture materials and the microscope ushered in the modern foundations of revascularization surgery, so will other technologies influence the future direction of this art. Developments in imaging techniques, especially of dynamic blood flow, will better guide surgeons to select patients that would benefit from surgery. Improvements in anastomotic techniques, especially obviating the need for temporary occlusion, will make this form of surgery safer and perhaps easier to impart onto future generations of surgeons. Less invasive techniques, such as endovascular surgery will also contribute as an important part of the cerebrovascular surgeon's armamentarium against ischemic damage to the brain.

\section{Conclusions}

Cerebral revascularization has developed from the culmination of several technologies, from the early beginnings of vascular surgical techniques in animals, to the development of the microscope, the bipolar coagulation, and suitable suture material. Its history has been marked by the successful interdisciplinary collaboration of key personalities, some of whom have been mentioned here. Major questions concerning the indications and benefits of cerebral revascularization are being addressed and interest in further advancing this field to make it safer for patients remains strong. Important research into perioperative blood flow assessment will play an important role in determining the success of cerebral revascularization. It is hoped that with better understanding of the pathophysiology of cerebral ischemia and better patient selection, cerebral revascularization will remain an important tool in contemporary neurosurgery.

\section{Disclaimer}

The authors report no conflict of interest concerning the materials or methods used in this study or the findings specified in this paper.

\section{References}

1. Anonymous: Failure of extracranial-intracranial arterial bypass to reduce the risk of ischemic stroke. Results of an international randomized trial. The EC/IC Bypass Study Group. N Engl J Med 313:1191-1200, 1985

2. Anonymous: The International Cooperative Study of Extracranial/Intracranial Arterial Anastomosis (EC/IC Bypass 
Study): methodology and entry characteristics. The EC/IC Bypass Study group. Stroke 16:397-406, 1985

3. Amin-Hanjani S, Butler WE, Ogilvy CS, Carter BS, Barker FG II: Extracranial-intracranial bypass in the treatment of occlusive cerebrovascular disease and intracranial aneurysms in the United States between 1992 and 2001: a population-based study. J Neurosurg 103:794-804, 2005

4. Ausman JI, Diaz FG: Critique of the extracranial-intracranial bypass study. Surg Neurol 26:218-221, 1986

5. Ausman JI, Diaz FG, Sadasivan B, Gonzeles-Portillo M Jr, Malik GM, Deopujari CE: Giant intracranial aneurysm surgery: the role of microvascular reconstruction. Surg Neurol 34:8-15, 1990

6. Ausman JI, Diaz FG, Vacca DF, Sadasivan B: Superficial temporal and occipital artery bypass pedicles to superior, anterior inferior, and posterior inferior cerebellar arteries for vertebrobasilar insufficiency. J Neurosurg 72:554-558, 1990

7. Awad IA, Spetzler RF: Extracranial-intracranial bypass surgery: a critical analysis in light of the International Cooperative Study. Neurosurgery 19:655-664, 1986

8. Barnett HJ, Fox A, Hachinski V, Haynes B, Peerless SJ, Sackett D, et al: Further conclusions from the extracranial-intracranial bypass trial. Surg Neurol 26:227-235, 1986

9. Beck CM, McKhann FC, Belnap, WD: Revascularization of the brain through establishment of a cervical arteriovenous fistula. J Pediatr 35:317-329, 1949

10. Bollman J: The animal with an Eck fistula. Physiol Rev 41:607, 1961

11. Bremmer JP, Verweij BH, Van der Zwan A, Reinert MM, Beck HJ, Tulleken CA: Sutureless nonocclusive bypass surgery in combination with an expanded polytetrafluoroethylene graft. Laboratory investigation. J Neurosurg 107:1190-1197, 2007

12. Carrel A: Nobel Prize in Physiology or Medicine 1912. Amsterdam: Elsevier Publishing Company, 1967

13. Chang SD, Ryu SI, Steinberg GK: Posterior cerebral circulation revascularization. Neurosurg Clin N Am 12:519-540, viii, 2001

14. Chmayssani M, Festa JR, Marshall RS: Chronic ischemia and neurocognition. Neuroimaging Clin N Am 17:313-324, 2007

15. Couldwell WT, Zuback J, Onios E, Ahluwalia BS, Tenner M, Moscatello A: Giant petrous carotid aneurysm treated by submandibular carotid-saphenous vein bypass. Case report. J Neurosurg 94:806-810, 2001

16. Day AL, Rhoton AL Jr, Little JR: The extracranial-intracranial bypass study. Surg Neurol 26:222-226, 1986

17. Derdeyn CP, Gage BF, Grubb RL Jr, Powers WJ: Cost-effectiveness analysis of therapy for symptomatic carotid occlusion: PET screening before selective extracranial-to-intracranial bypass versus medical treatment. J Nucl Med 41:800-807, 2002

18. Derdeyn CP, Videen TO, Simmons NR, Yundt KD, Fritsch SM, Grubb RL Jr, et al: Count-based PET method for predicting ischemic stroke in patients with symptomatic carotid arterial occlusion. Radiology 212:499-506, 1999

19. Derdeyn CP, Yundt KD, Videen TO, Carpenter DA, Grubb RL Jr, Powers WJ: Increased oxygen extraction fraction is associated with prior ischemic events in patients with carotid occlusion. Stroke 29:754-758, 1998

20. Donaghy RM: The history of microsurgery in neurosurgery. Clin Neurosurg 26:619-625, 1979

21. Fisher C: Occlusion of the internal carotid artery. Arch Neurol Psych 65:346-377, 1951

22. Friedman JA, Piepgras DG: Current neurosurgical indications for saphenous vein graft bypass. Neurosurg Focus 14(3):e1, 2003

23. Fukui M: Current state of study on moyamoya disease in Japan. Surg Neurol 47:138-143, 1997

24. German WJ, Taffel W: Surgical production of collateral in- tracranial circulation: an experimental study. Proc Soc Exp Biol Med 42:349-353, 1939

25. Grubb RL Jr, Derdeyn CP, Fritsch SM, Carpenter DA, Yundt $\mathrm{KD}$, Videen TO, et al: Importance of hemodynamic factors in the prognosis of symptomatic carotid occlusion. JAMA 280:1055-1060, 1998

26. Grubb RL Jr, Powers WJ, Derdeyn CP, Adams HP Jr, Clarke WR: The Carotid Occlusion Surgery Study. Neurosurg Focus 14(3):e9, 2003

27. Hankey GJ, Warlow CP: The role of imaging in the management of cerebral and ocular ischaemia. Neuroradiology 33:381-390, 1991

28. Harms HMG, Blodi FC: Ocular Surgery Under the Microscope. Chicago: Year Book Medical Publishers, 1967

29. Houkin K, Kamiyama H, Kuroda S, Ishikawa T, Takahashi A, Abe H: Long-term patency of radial artery graft bypass for reconstruction of the internal carotid artery. Technical note. J Neurosurg 90:786-790, 1999

30. Jacobson JH II, Wallman LJ, Schumacher GA, Flanagan M, Suarez EL, Donaghy RM: Microsurgery as an aid to middle cerebral artery endarterectomy. J Neurosurg 19:108-115, 1962

31. Jacobson JH II, Suarez EL: Microsurgery in anastomosis of small vessels. Surg Forum 11:243-245, 1960

32. JET Study Group: Japanese EC-IC Trial (JET Study): study design and interim analysis. Surg Cereb Stroke (Jpn):97100,2002

33. Jinnouchi J, Toyoda K, Inoue T, Fujimoto S, Gotoh S, Yasumori K, et al: Changes in brain volume 2 years after extracranial-intracranial bypass surgery: a preliminary subanalysis of the Japanese EC-IC trial. Cerebrovasc Dis 22:177-182, 2006

34. Karasawa J, Kikuchi H, Furuse S, Kawamura J, Sakaki T: Treatment of moyamoya disease with STA-MCA anastomosis. J Neurosurg 49:679-688, 1978

35. Karasawa J, Touho H, Ohnishi H, Miyamoto S, Kikuchi H: Long-term follow-up study after extracranial-intracranial bypass surgery for anterior circulation ischemia in childhood moyamoya disease. J Neurosurg 77:84-89, 1992

36. Kawaguchi S, Noguchi H, Sakaki T, Morimoto T, Hoshida T, Yonezawa T, et al: Evaluating the effect of superficial temporal artery to middle cerebral artery bypass on pure motor function using motor activation single photon emission computed tomography. Neurosurgery 41:1065-1072, 1997

37. Klijn CJ, Kappelle LJ, Tulleken CA, van Gijn J: Symptomatic carotid artery occlusion: a reappraisal of hemodynamic factors. Stroke 28:2084-2093, 1997

38. Krayenbuhl HA: The moyamoya syndrome and the neurosurgeon. Surg Neurol 4:353-360, 1975

39. Krayenbühl H, Yaşargil MG: Zebrale Angiographie für Klinik und Praxis. Stuttgart: Thieme, 1965

40. Kredel FE: Collateral cerebral circulation by muscle graft: technique of operation with report of 3 cases. South Surgeon 10:235-244, 1942

41. Kriss TC, Kriss VM: History of the operating microscope: from magnifying glass to microneurosurgery. Neurosurgery 42:899-908, 1998

42. Kurze T: Microtechniques in neurological surgery. Clin Neurosurg 11:128-137, 1964

43. Lawton MT, Hamilton MG, Morcos JJ, Spetzler RF: Revascularization and aneurysm surgery: current techniques, indications, and outcome. Neurosurgery 38:83-84, 1996

44. Liu JK, Couldwell WT: Interpositional carotid artery bypass strategies in the surgical management of aneurysms and tumors of the skull base. Neurosurg Focus 14(3): 22, 2003

45. Liu JK, Kan P, Karwande SV, Couldwell WT: Conduits for cerebrovascular bypass and lessons learned from the cardiovascular experience. Neurosurg Focus 14(3):e3, 2003

46. Matsushima T, Inoue T, Suzuki SO, Fujii K, Fukui M, Hasuo 
K: Surgical treatment of moyamoya disease in pediatric patients-comparison between the results of indirect and direct revascularization procedures. Neurosurgery 31:401-405, 1992

47. McIvor NP, Willinsky RA, TerBrugge KG, Rutka JA, Freeman JL: Validity of test occlusion studies prior to internal carotid artery sacrifice. Head Neck 16:11-16, 1994

48. Miyamoto S: Study design for a prospective randomized trial of extracranial-intracranial bypass surgery for adults with moyamoya disease and hemorrhagic onset-the Japan Adult Moyamoya Trial Group. Neurol Med Chir (Tokyo) 44:218219, 2004

49. Miyazaki S, Fukushima T, Fujimaki T: Resection of high-cervical paraganglioma with cervical-to-petrous internal carotid artery saphenous vein bypass. Report of two cases. J Neurosurg 73:141-146, 1990

50. Murata Y, Katayama Y, Sakatani K, Fukaya C, Kano T: Evaluation of extracranial-intracranial arterial bypass function by using near-infrared spectroscopy. J Neurosurg 99:304-310, 2003

51. Nussbaum ES, Erickson DL: Extracranial-intracranial bypass for ischemic cerebrovascular disease refractory to maximal medical therapy. Neurosurgery 46:37-33, 2000

52. Nylén CO: The otomicroscope and microsurgery 1921-1971. Acta Otolaryngol 73:453-454, 1972

53. Ogasawara K, Ogawa A: [JET study (Japanese EC-IC Bypass Trial).] Nippon Rinsho 64 (Suppl 7):524-527, 2006 (Jpn)

54. Onesti ST, Solomon RA, Quest DO: Cerebral revascularization: a review. Neurosurgery 25:618-619, 1989

55. Pool DP, Potts DG: Aneurysms and Arteriovenous Anomalies of the Brain: Diagnosis and Treatment. New York: Harper \& Row, 1965

56. Powers WJ, Derdeyn CP, Fritsch SM, Carpenter DA, Yundt $\mathrm{KD}$, Videen TO, et al: Benign prognosis of never-symptomatic carotid occlusion. Neurology 54:878-882, 2000

57. Reinert M, Verweij BH, Schaffner T, Mihalache G, Schroth G, Seller RW, et al: Expanded polytetrafluoroethylene graft for bypass surgery using the excimer laser-assisted nonocclusive anastomosis technique. J Neurosurg 105:758-764, 2006

58. Sasoh M, Ogasawara K, Kuroda K, Okuguchi T, Terasaki K, Yamadate K, et al: Effects of EC-IC bypass surgery on cognitive impairment in patients with hemodynamic cerebral ischemia. Surg Neurol 59:455-463, 2003

59. Schmiedek P, Gratzl O, Spetzler R, Steinhoff H, Enzenbach $\mathrm{R}$, Brendel W, et al: Selection of patients for extra-intracranial arterial bypass surgery based on rCBF measurements. J Neurosurg 44:303-312, 1976

60. Sekhar LN, Duff JM, Kalavakonda C, Olding M: Cerebral revascularization using radial artery grafts for the treatment of complex intracranial aneurysms: techniques and outcomes for 17 patients. Neurosurgery 49:646-649, 2001

61. Sekhar LN, Kalavakonda C: Cerebral revascularization for aneurysms and tumors. Neurosurgery 50:321-331, 2002

62. Sekhar LN, Sen CN, Jho HD: Saphenous vein graft bypass of the cavernous internal carotid artery. J Neurosurg 72:35-41, 1990

63. Spetzler R, Chater N: Occipital artery-middle cerebral artery anastomosis for cerebral artery occlusive disease. Surg Neurol 2:235-238, 1974

64. Spetzler RF, Carter L, Selman WR, Martin N: Cerebral Revascularization for Stroke. New York: Thieme-Stratton, 1985

65. Spetzler RF, Fukushima T, Martin N, Zabramski JM: Petrous carotid-to-intradural carotid saphenous vein graft for intracavernous giant aneurysm, tumor, and occlusive cerebrovascular disease. J Neurosurg 73:496-501, 1990

66. Sundt TM Jr: Was the international randomized trial of extracranial-intracranial arterial bypass representative of the population at risk? N Engl J Med 316:814-816, 1987

67. Sundt TM Jr, Fode NC, Jack CR Jr: The past, present, and future of extracranial to intracranial bypass surgery. Clin Neurosurg 34:134-153, 1988

68. Sundt TM Jr, Whisnant JP, Piepgras DG, Campbell JK, Holman CB: Intracranial bypass grafts for vertebral-basilar ischemia. Mayo Clin Proc 53:12-18, 1978

69. Tachibana E, Suzuki Y, Harada T, Saito K, Gupta SK, Yoshida $\mathrm{J}$ : Bypass surgery using a radial artery graft for bilateral extracranial carotid arteries occlusion. Neurosurg Rev 23:5255,2000

70. Tew JM Jr: M. Gazi Yaşargil: Neurosurgery's man of the century. Neurosurgery 45:1010-1014, 1999

71. Vernieri F, Pasqualetti P, Passarelli F, Rossini PM, Silvestrini M: Outcome of carotid artery occlusion is predicted by cerebrovascular reactivity. Stroke 30:593-598, 1999

72. Vishteh AG, Marciano FF, David CA, Schievink WI, Zabramski JM, Spetzler RF: Long-term graft patency rates and clinical outcomes after revascularization for symptomatic traumatic internal carotid artery dissection. Neurosurgery 43:761-768, 1998

73. Wanebo JE, Amin-Hanjani S, Boyd C, Peery T: Assessing success after cerebral revascularization for ischemia. Skull Base 15:215-227, 2005

74. Wilkins R, Wilkins GK: Neurosurgical Classics II. Rolling Meadows, IL: American Association of Neurological Surgeons, 2000

75. Woringer E, Kunlin J: [Anastomosis between the common carotid and the intracranial carotid or the Sylvian artery by a graft, using the suspended suture technic.] Neurochirurgie 200:181-188, 1963 (Fr)

76. Yamauchi H, Fukuyama H, Nagahama Y, Nabatame H, Ueno M, Nishizawa S, et al: Significance of increased oxygen extraction fraction in five-year prognosis of major cerebral arterial occlusive diseases. J Nucl Med 40:1992-1998, 1999

77. Yaşargil: Diagnosis and indications for operations in cerebrovascular occlusive disease, in Yaşargil (ed): Microsurgery Applied to Neurosurgery. Stuttgart: Georg Theime Berlag, Academic Press, 1969, pp 95-118

Manuscript submitted January 15, 2009.

Accepted March 6, 2009.

Address correspondence to: Marco Lee, M.D., Ph.D., F.R.C.S., Department of Neurosurgery, Stanford University Medical Center, 300 Pasteur Drive, Stanford, California 94305. email: marcolee@ stanford.edu. 